\title{
РАСЧЛЕНЕНИЕ ОРДОВИКСКИХ ОТЛОЖЕНИИ РАЗРЕЗА СКВ. БЕРЗИНИ (ЮГО-ВОСТОЧНАЯ ЛАТВИЯ)
}

Скв. Берзини (Морозики) пробурена в ходе проведения среднемасштабной геолого-гидрогеологической съемки в районе Юго-Восточной Латвии, пограничном с Белоруссией (см. рисунок). В тектоническом плане скважина находится в южной части Латвийской седловины, расположенной на стыке двух крупных структурных элементов ВосточноЕвропейской платформы - Московской и Балтийской синеклиз. До сих пор мы располагали отсюда только предварительными данными расчленения разреза скв. Лудза (Гайлите, Ульст, 1972).

Ордовикские отложения мощностью 74,0 м в скв. Берзини пройдены в интервале $412,0-486,0$ м (при определении глубин данные каротажа не учитывались). Эти отложения в основном карадокского возраста. В разрезе скважины они перекрываются девонскими зеленовато-серыми песчаниками и алевролитами. Верхи ордовика здесь уничтожены в результате додевонской денудации. Скважина закрыта на глубине $486,0 \mathrm{M}$.

Ниже приводятся литологическое описание (составил Л. Пылма) и стратиграфическое расчленение этого разреза на основании изучения 200 образцов макрофауны (Л. Хинтс), 53 образцов остракод (Л. Сарв) и 94 образцов кислотоустойчивых микрофоссилий (данные Р. Мянниля).

Авторы искренне благодарны сотрудникам геологоразведочной экспедиции Управления геологии СМ Латвийской ССР за предоставление возможности изучения керна скв. Берзини и отбора образцов на исследование микро- и макрофауны. Авторы статьи признательны коллеге Р. Мяннилю за помощь при определении некоторых групп макрофауны и за предоставление данных о распространении кислотоустойчивых микрофоссилий в рассматриваемом разрезе.

\section{Описание керна скв. Берзини (сверху вниз)}

1. 412,0-426,4 (мощность $14,4 м$ ). Известняк от чистого до среднеглинистого, глинистость уменьшается к верху, в верхней половине интервала порода сильно доломитизирована (до доломита), от микро- до тонкокристаллического, мелкодетритистый, прослоями до мелкодетритового (преобладает водорослевый детрит), светло-серый с коричневатым или зеленоватым оттенком, в мергелистых прослоях много темно-коричневого или черного органического материала, от средне-до толстослоистого, текстура обусловлена слабоволнистыми, иногда разветвляющимися прослойками и прослоями (мощностью до 7 cm) коричневато- 
серого известкового или доломитистого (в верхней части) мергеля. Контакты с известняком четкие.

Верхний контакт интервала резкий: карбонатные породы ордовика покрываются девонскими песчаниками и алевролитами. Нижняя граница интервала переходная.

На гл. 424,4 и 424,85 м прослеживаются слабо выраженные пиритизированные поверхности перерыва. На гл. 412,5, 413,7, 415,0 и 416,5 м встречаются скопления вторичного гипса (по трещинам и кавернам). На гл. 419,0 $м$ обнаружены редкие чешуйки биотита.

2. 426,4-429,5 (мощность 3,1 м). Известняк от слабо-до сильноглинистого, микрокристаллический, в основном мелкодетритистый, зеленоватосерый, среднеслоистый, текстура обусловлена слабоволнистыми прослойками и прослоями (мощностью до 2 см) серовато-зеленого известкового мергеля. Нижняя граница интервала переходная.

На гл. 428,3 и 428,7 $м$ встречаются слабо выраженные пиритизированные поверхности перерыва. На гл. 427,4 м много горизонтальных ходов илоедов диаметром $1-2$ мм.

3. 429,5-433,5 (мощность 4,0 м). Мергель известковый, прослоями глинистый, от мелкодетритистого до мелкодетритового, сероватозеленый, неяснослоистой текстуры, с присутствием, по-видимому, тонкорассеянного глауконита. Нижняя граница переходная.

В интервале встречаются отдельные комки (диаметром до 5 см) и прослои (мощностью до 2 см) слабоглинистого микрокристаллического известняка. На гл. 432,8 м слабо выраженная пиритизированная поверхность перерыва.

4. 433,5-439,1 (мощность 5,6 м). Известняк от слабо-до сильноглинистого, микрокристаллический с прослоями (до 15 cм) глинистого скрытокристаллического известняка, мелкодетритистый, детрит местами слабо пиритизированный, светло-серый с зеленоватым оттенком, от средне- до тонкослоистого, текстура обусловлена прослоями (до 10 см) известкового и глинистого мергеля зеленовато-серого цвета. В прослоях мергеля, по-видимому, присутствует тонкорассеянный глауконит. Нижняя граница интервала резкая.

Для описанного интервала характерны прослои мощностью до $5 \mathrm{~cm}$ со скоплениями более или менее целых скелетных остатков организмов (в основном брахиопод, реже мшанок). На гл. 436,6 м много горизонтальных ходов илоедов диаметром $1-3$ см. На гл. 435,8, 436,7 и 439,1 м прослеживаются пиритизированные поверхности перерыва. Первая из них сильно выражена.

5. 439,1-450,8 (мощность 11,7 м). Известняк от чистого до сильноглинистого (преобладает последний), скрытокристаллический, с редким мелким частично пиритизированным детритом, зеленовато-серый, среднеслоистый, текстура обусловлена волнистыми прослойками и тонкими (до 2 cм) прослоями зеленовато-серого (в верхней части с коричневатым оттенком) известкового мергеля. Нижняя граница переходная.

Особенно в нижней и верхней части интервала прослеживаются мелкие темные пиритизированные пятна. В мергелистых прослоях много сплюснутых горизонтальных ходов илоедов днаметром $1-3 \mathrm{~cm}$. Часто (иногда через $10-30$ см) встречаются прослои со скоплениями более или менее целых остатков организмов. Мощность прослоев обычно в пределах $1-3$ см, в единичных случаях до 20 см. На гл. 440,15, 441,8, 449,5, 450,4 и 450,8 $м$ обнаружены пиритизированные поверхности перерыва.

6. 450,8-457,3 (мощность 6,5 м). Известняк от слабо- до среднеглинистого (преобладает последний), скрытокристаллический, с редкими 
включениями до микрокристаллического, в верхней половине содержит мелкий детрит, светло-серого цвета с зеленоватым оттенком, текстура тонкослоистая, обусловленная прослойками и прослоями (до 20 см) зеленовато-серого известкового и реже глинистого мергеля массивной текстуры. Местами мергель преобладает в разрезе, особенно в пределах нижнего метра. По-видимому, в интервале присутствует тонкорассеянный глауконит. Нижняя граница интервала резкая.

Для этого интервала, как для четвертого и пятого, характерны послойные $(1-2$ см) скопления более или менее целых скелетных остатков (главным образом брахиопод). На гл. 454,8 $\mu$ встречена метабентонитоподобная глина (около $1 \mathrm{~cm}$ ) с обильным содержанием чешуек биотита. Редкие чешуйки биотита обнаружены также на гл. 455,2 м. Пиритизированные поверхности перерыва зафиксированы на гл. 452,7, 453,7, 455,7 и $457,3 \mu$.

7. 457,3-470,0 (мощность 12,7 м). Известняк от средне- до сильноглинистото (глинистость уменьшается к верху), в пределах верхнего метра слабодоломитизированный, микрокристаллический, от мелкодетритистого до мелкодетритового, детрит в верхней половине интервала частично пиритизированный, светло-серый с зеленоватым оттенком, от средне- до тонкослоистого, текстура обусловлена слабоволнистыми прослойками и прослоями (до 2 см) зеленовато-серого известкового мергеля, который местами преобладает в разрезе. Контакты между известняком и мергелем нерезкие. Нижняя граница интервала переходная.

На гл. 458,4 м много горизонтальных ходов илоедов диаметром $1-2$ мм. На гл. $458,1,459,0,461,9$ и 462,7 м встречаются скопления чешуек биотита, которые представляют собой, по-видимому, периферийные аналоги метабентонитовых прослоев, развитых в Западной Прибалтике. На гл. 462,7 $м$ прослеживается слабо выраженная пиритизированная поверхность перерыва.

8. 470,0-486,0 (мощность 16,0 м). Мергель известковый, мелкодетритистый, прослоями до мелкодетритового, зеленовато-серый (светлый), с отдельными прослоями (до 5 cм) и комками (размером до $2 \times 5$ cм) светло-серого детритистого среднеглинистого микрокристаллического известняка. Контакты между мергелем и известняком относительно резкие.

\section{Некоторые особенности литологии разреза}

Изученный разрез (рисунок) отличается от западных и особенно северных (район выходов) разрезов большей глинистостью пород. Здесь преобладают сильноглинистые известняки и известковые мергели. Наименее глинистой частью разреза является верхняя половина интервала $412-426,4$, породы которой по ряду литологических признаков (присутствию органики и коричневому цвету, значительному содержанию водорослевого детрита, незначительной (менее $10 \%$ ) глинистости и т. д.) напоминают известняки моэской пачки пиргуского горизонта ( $\left.\mathrm{F}_{1} \mathrm{cM}\right)$ Северной Эстонии.

Верхней части первого интервала свойственна сильная вторичная доломитизация (до доломита) первичных известняков, обычно характерная для ордовикско-силурийских карбонатных пород, залегающих непосредственно ниже девонских отложений. Незначительная вторичная доломитизация (содержание доломита до 15\%) приходится и на интервал 457,8-459,2 м. В остальной части разреза среднее содержание доломита (на основе 23 анализов) составляет 5,5\%, т. е. практически не отли- 
чается от среднего содержания доломита $(5,1 \%)$, вычисленного для вторично недоломитизированных разрезов Северной и Средней Прибалтики (Пылма, 1972а, б).

Для интервала 433,5-457,3 $м$ характерны частые (местами через 10-30 см) прослои со скоплениями более или менее целых скелетных остатков организмов мощностью обычно в пределах $1-3$ cм, в единичных случаях до 20 см. Эти скопления цельнораковинного материала содержат еще полидетрит разных размеров и неравномерной окатанности, а также сгустки и хорошо окатанный известняковый обломочный материал диаметром до 5 см с неравномерной пиритовой импрегнацией. В более мощных прослоях (свыше 4 cм) глинистый материал обычно отсутствует, а остатки организмов и их детрит сцементированы прозрачным вторичным кальцитом. Среди сравнительно целых скелетных остатков организмов преобладают створки замковых брахиопод, реже прослеживаются скопления мшанок, трилобитов и гастропод. Аналогичные скопления цельнораковинного материала встречаются в северной (эстонской) и реже в осевой (латвийской) структурно-фациальных зонах на разных стратиграфических уровнях, но чаще в интервале $\mathrm{D}_{\mathrm{II}}-\mathrm{F}_{\mathrm{II}}$. Однако численность цельнораковинных прослоев в интервале 433,5457,3 м скв. Берзини не идет ни в какое сравнение с отмеченными выше структурно-фациальными зонами. Такие прослои цельнораковинного (в основном чистозернистого) материала в относительно глинистых карбонатных отложениях указывают, по-видимому, на частые вертикальные колебательные тектонические движения дна бассейна и на существенную дифференциацию его рельефа.

Следует подчеркнуть, что в изученном разрезе довольно четко прослеживается граница (на гл. 457,3 м) между двумя этапами карбонатного осадконакопления в Балтийском бассейне (Пылма, 1973). Ниже этого контакта залегают микрокристаллические средне- и сильноглинистые известняки и известковые мергели, а выше - преобладают скрытокристаллические известняки различной степени глинистости с частыми прослоями цельнораковинного материала и редкими прослоями мергелей, а также сравнительно чистые карбонатные породы, обогащенные водорослевым детритом.

\section{Расчленение разреза скв. Берзини по макро- и микрофауне}

М а крофаун а в ордовикских отложениях разреза скв. Берзини по групповому составу весьма разнообразна. В іластоящей работе основное внимание уделяется изучению брахиопод и трилобитов, в меньшей мере - мшанок, иглокожих и других групп. По макрофауне исследуемые отложения можно расчленить на три части: идавереско-йыхвискокейласкую $(457,3-480 \mu)$, оандуско-ракверескую $(440-457,3 \quad$ м) и верхнеордовикскую $(425,7-440 \mathrm{M})$.

Нижняя часть разреза относительно бедна макрофауной. Здесь вплоть до предполагаемой верхней границы идавереского горизонта $(462,7$ м встречаются в основном Ristnacrinus angulatus Jeltyscheva, Saukrodictya sp., Estoniops bekkeri Männil, Bilobia aff. musca Öpik (cм. рисунок). В пределах Прибалтики первые три вида не известны ниже идавереского горизонта. Некоторое обновление макрофауны на глубине около 470 м обусловлено, вероятно, местным изменением фациальных условий (ср. распределение остракод).

Комплекс фауны, установленный в верхней половине идавереского горизонта, весьма сходен с таковым в одновозрастных отложениях неко- 


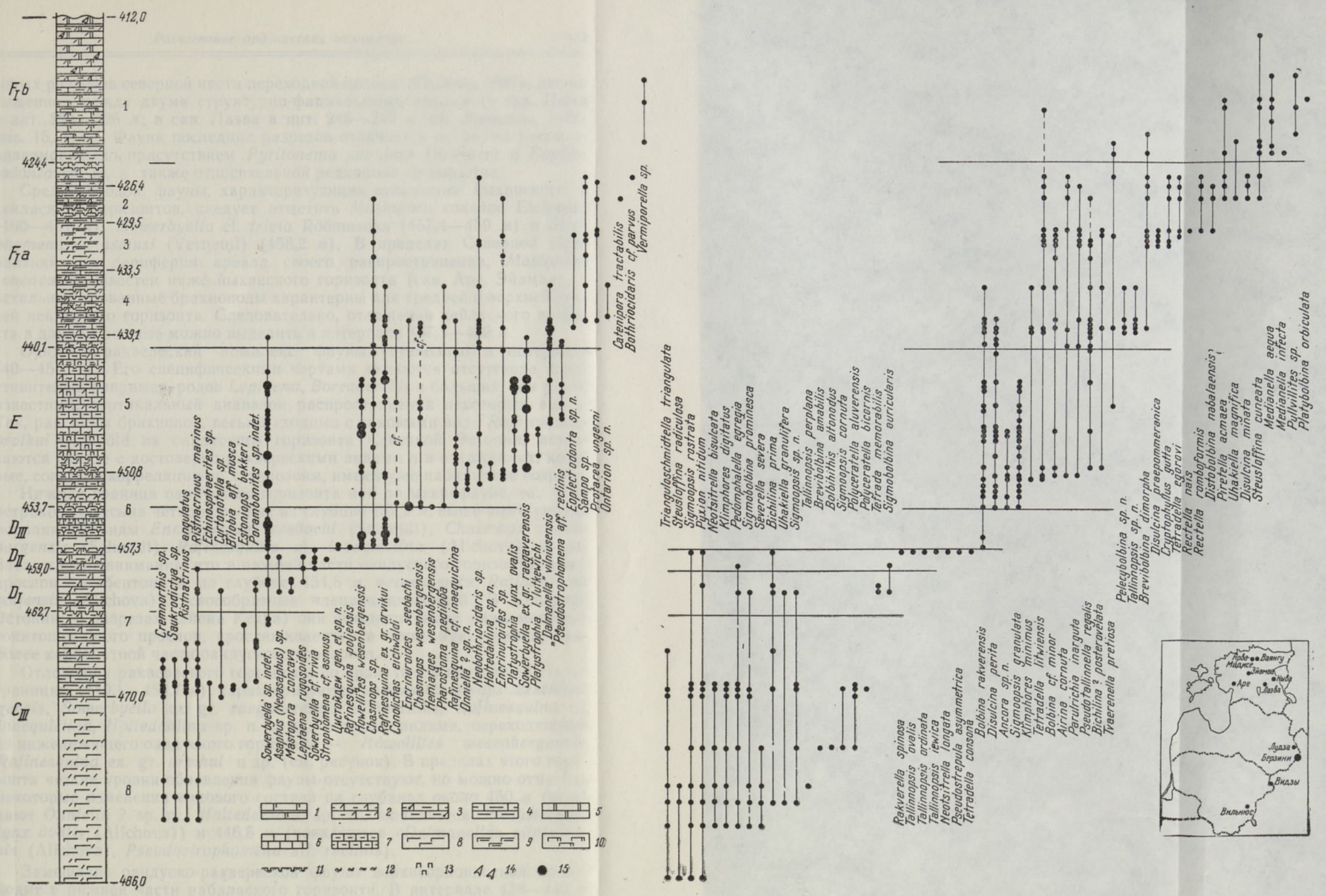

Расчленение разреза скв. Берзини с распределеннем изученных групп фауны.

1 - известняк чистый, доломитистый с тонкими прослоями мергелей; 2 - известняк слабоглиннстый (содержание нерастворимого сстатка $і 0$ - $15 \%$ ), мслко детритовый; 3 - известняк среднеглинистый (15-20\%), мелкодетритистый, детрит пиритизированный; 4 - известняк сильноглинистый (20-25\%); 5 - доломит; 6 - известняк скрытокристаллический, 7 - известняк скрытокристаллический, глинистый (10-25\%); 8 - мергель известковый; 9 - мергель глини стый: 10 - мергель доломитистый, известковый; 11 - поверхность перерыва; 12 - горизонтальные ходы илоедов; 13 - пиритизированные пятна; 14 - про-

явления гипса; 15 - массовое распространение вида.

$\mathrm{C}_{\text {II }}$ - идавереский, $\mathrm{D}_{\mathrm{I}}$ - йыхвиский, $\mathrm{D}_{\mathrm{II}}$ - кейлаский, $\mathrm{D}_{\mathrm{IH}}$ - оандуский, $\mathrm{E}-\mathrm{pakвереский,} \mathrm{F}_{\mathrm{I}} \mathrm{a}$ - набалаский, $\mathrm{F}_{\mathrm{I}} \mathrm{b}-$ вормсиский. На правой стороне колонки - порядковые номера и глубина залегания границ литологических комплексов. 
торых разрезов северной части переходной полосы (Пылма, 1967), расположенной между двумя структурно-фациальными зонами (в скв. Ныва в инт. $224-226 \mu ;$ в скв. Лаэва в инт. 246-249 м; см. Мянниль, 1966, рис. 15,17$)$. Фауна последних разрезов отличается от фауны рассматриваемого лишь присутствием Pyritonema subulare (Roemer) и Eoplectodonta sp. n., а также относительной редкостью кремнортид.

Среди находок фауны, характеризующих отложения йыхвиского и кейлаского горизонтов, следует отметить Mastopora concava Eichwald (460-461 м), Sowerbyella cf. trivia Rõõmusoks $(457,4-459$ м) и Strophomena cf. asmusi (Verneuil) (458,2 м). В пределах Северной Прибалтики, на периферии ареала своего распространения, Mastopora concava не известен ниже йыхвиского горизонта (скв. Аре, Эйамаа), а остальные названные брахиоподы характерны для средней и верхней частей кейлаского горизонта. Следовательно, отложения кейлаского возраста в данном разрезе можно выделить в интервале 457,3-459 $\mathrm{M}$.

Оандуско-раквереский комплекс фауны установлен в интервале $440-457,3 \mu$. Его специфическими чертами являются отсутствие представителей, например, родов Leptaena, Boreadorthis и бо́льший, чем ранее известный, вертикальный диапазон распространения некоторых видов. Так, раковины брахиопод, весьма сходные с таковыми вида Rafinesquina orvikui Oraspõld из оандуского горизонта Северной Әстонии, встречаются вместе с достоверно ракверескими видами и в отложениях, которые, согласно корреляции по хитинозоям, имеют уже набалаский возраст.

Нижняя граница оандуского горизонта как по макрофауне, так и по остракодам весьма четко проходит на глубине 457,3 , выше этого уровня появляются виды Encrinuroides seebachi (Schmidt), Chasmops wesenbergensis (Schmidt), Rafinesquina cf. inaequiclina (Alichova) и др. Заслуживает внимания, что в нижней части оандуского горизонта, ниже прослоя метабентонита на глубине 454,8 м, встречаются Rafinesquina poljensis (Alichova) и своеобразные членики цистоидей. В Северной Әстонии (в разрезах района Кехра) они исчезают также ниже метабентонитоподобного прослоя, прослеживаемого в основании верхней, наиболее карбонатной части оандуского горизонта.

Отложения раквереского горизонта, по принятым в настоящей статье границам $(440,1-453,7$ м), характеризуются видами Chasmops wesenbergensis, Sowerbyella ex gr. raegaverensis Rõõmusoks, Rafinesquina cf. inaequiclina, Holtedahlina sp. п. и др., а также видами, переходящими из нижележащего оандуского горизонта - Howellites wesenbergensis, Rafinesquina ex. gr. orvikui и др. (см. рисунок). В пределах этого горизонта четкие уровни обновления фауны отсутствуют, но можно отметить некоторые изменения видового состава на глубинах около 450 м (исчезают Onniella ? sp. n., Holtedahlina sp. п., появляется Platystrophia lynx ovalis (Alichova)) и 446,5 м (появляются «Dalmanella» vilniusensis (Alichova), Pseudostrophomena aff. reclinis).

Замещение оандуско-раквереской фауны верхнеордовикской происходит в нижней части набалаского горизонта. В интервале $438-440 \mathrm{M}$ исчезают, например, Conolichas cf. eichwaldi (Nieszkowskii), Pseudostrophomena aff. reclinis и появляются Protarea ungerni (Eichwald), Eoplectodonta sp. п. Но некоторые виды («Dalmanella» vilniusensis, Rafinesquina ex. gr. orvikui), переходящие из раквереского горизонта, выше $\sim 435 \mu$ не встречаются (см. также распространение остракод). Отложения, представленные переходным комплексом макрофауны $(438-440$ м), четко прослеживаются по частым находкам видов \&Dalmanella» vilniusensis, Neobothriocidaris sp. и др. (см. рисунок). Возможно, что первый из них характерен только для разрезов Юго-Восточной При- 
балтики. Его присутствне обнаружено еще в разрезах Вильнюс (см. Алихова, Балашова, Балашов, 1954) и Видзы (определения автора).

Верхнеордовикский комплекс фауны, установленный в ннтервале 425-438 м, не содержит видов, которые бы достоверно отрицали предположение о набаласком возрасте отложений этого интервала по остракодам. Представители родов Sampo и Skenidioides, обнаруженные в указанных выше переходных слоях, и мшанки Glauconomella ? strigosa (Billings) и др., найденные в верхней половине горизонта (425,6430,6 м), появляются в разрезах Северной Эстонии в набаласком горизонте. Только табуляты Protarea ungerni (Eichwald) (426-437,8 $м$ ) и Catenipora tractabilis (Sokolov) известны в Северной Прибалтике на более высоком стратиграфическом уровне (см. Кальо, Клааманн, Нестор, 1963 , с. 78 ; Клааманн, 1966).

О стр коды можно подразделить также на идавереско-йыхвискокейласкую, оандуско-ракверескую и верхнеордовикскую ассоциации. Распространение наиболее типичных их представителей показано на рисунке.

Идавереско-йыхвиско-кейлаская богатая ассоциация остракод (на-

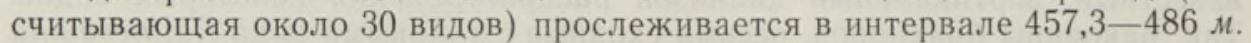
Характерно, что здесь преобладают идавереско-йыхвиские виды. Такие представители, как Trianguloschmidtella triangulata Sarv, Steusloffina radiculosa Neckaja, Severella severa (Sarv), Sigmoopsis sp. n., S. cornuta (Krause), Bolbihithis altonodus (Sarv) и весьма редкий, приуроченный только к верхней части интервала Tetrada memorabilis (Neckaja), нигде в Прибалтике за пределами идавереского и йыхвиского горизонтов не установлены. Виды, которые позволили бы разграничить эти горизонты, в данном разрезе отсутствуют.

Нижняя граница кейлаского горизонта не поддается четкому определению по остракодам из-за малого количества обработанных образцов. Характерные для идавереско-йыхвиской ассоциации виды Sigmoopsis sp. n. и Uhakiella granulifera (Ulrich et Bassler) продолжают встречаться и на глубине 460,8 м, a Tetrada memorabilis даже на глубине 460,2 м. Отсутствие типичных идавереско-йыхвиских видов в образце с глубины 458,5 $м$ позволяет провести эту границу на уровне $459 м$. Остракоды Tallinnopsis ovalis Sarv и $T$ ordinata Sarv, наряду с видами более широкого вертикального распространения в образце с глубины $457,4 \mu$, подтверждают уже позднекейлаский возраст содержащих их отложений.

На глубине 457,2 м кейлаской ассоциации остракод уже нет. Появление здесь Bolbina rakverensis Sarv свидетельствует о начале распространения новой - оандуско-раквереской ассоциацин. Таким образом, распространение остракод подтверждает правильность принятой границы между кейласким и оандуским горизонтами.

Bolbina rakverensis является единственным видом, встреченным в интервале 453,7-457,3 м, который по другим группам фауны выделен как оандуский горизонт. Появление типичных представителей оандускораквереской ассоциации во главе с Disulcina perita (Sarv), Sigmoopsis granulata (Sarv), Ancora sp. n. начинает прослеживаться с глубины $453,6 м$, т. е. в отложениях раквереского возраста. Несколько выше по разрезу, в интервале 450,0-451,3 м, к ним присоединяются Klimphores minimus (Sarv), Bolbina cf. minor (Krause) и Bichilina ? posterovelata Sarv вместе с Tetradella litwiensis Neckaja и Pseudotallinnella regalis (Neckaja). Из перечисленных видов Disulcina perita и Klimphores minimus на территории Әстонии в отложениях моложе раквереского возраста 
до сих пор не установлены (Сарв, 1959), но в данном разрезе они обнаружены еще в ннтервале 434,9-440,1 , который, по принятому в данной статье расчленению, относится к нижней части набалаского горизонта. Значительно раньше, чем в эстонских разрезах, уже в низах раквереского горизонта, появляется Airina cornuta (Neckaja) - типичный представитель верхнеордовикской ассоциации. Из сказанного выше следует, что уровень 440,1 м, принятый по распространению остракод за границу между раквереским и набаласким горизонтами, нельзя считать точно установленным, хотя в пользу проведения границы именно на этом уровне говорят обнаруженные немного выше Brevibolbina dimorpha Sarv, Pelecybolbina sp. п. и Tallinnopsis sp. п. Названные новые виды ограниченного вертикального, но довольно широкого горизонтального распространения установлены примерно на таком же уровне в разрезах Средней Эстонии (скв. Ярва-Мадизе, Ваянгу).

Верхняя часть набалаского горизонта $(426,4-430,1$ м) представлена в первую очередь Distobolbina nabalaensis Sarv, обычно приуроченным только к отложениям этого возраста, а также Disulcina praepommeranica Schallreuter, Cryptophyllus gutta Schallreuter и Tetradella egorovi Neckaja, Rectella romboformis Neckaja, $R$. nais Neckaja.

Все эти виды характерны для верхнеордовикской ассоциации остракод. К этой же категории относятся появляющиеся в самой верхней части набалаского горизонта Piretella acmaea Öpik, Uhakiella magnifica Sarv и Steusloffina cuneata (Steusloff). Последние три вида обнаружены в данном разрезе и в отложениях вормсиского возраста вместе с Medianella aequa (Stumbur), M. intecta (Stumbur) и Platybolbina orbiculata Sarv. Bсе они относятся к видам широкого вертикального распространения, обильно встречающимся в отложениях всех горизонтов верхнего ордовика Прибалтики.

Хитинозои (данные Р. Мянниля). В интервале $477,1-485,0$ м установлен Eremochitina dalbyensis Laufeld. Согласно Р. Мяннилю (1972), распространение этого вида ограничивается нижней частью идавереского горизонта, что хорошо согласуется с данными по макрофауне и остракодам.

Находка Cyathochitina dispar Taug. в образце с глубины 439,8 м позволяет (Mannil, 1971) провести нижнюю границу набалаского горизонта по поверхности перерыва на глубине 440,1 $\boldsymbol{M}$.

Итак, в разрезе скв. Берзини представлены верхняя часть среднего и низы верхнего ордовика, т. е. отложения почти всего карадокского яруса. Данные фауны более или менее четко обосновывают все горизонты с принятыми выше границами. В дополнительном изучении нуждаются самые верхи разреза, т. е. вормсиский горизонт (на основе материалов с более обширной территории), а также расположение границы между раквереским и набаласким горизонтами.

Разрез скв. Лудза, предварительное расчленение которого дают Л. Гайлите и Р. Ульст (1972), непосредственно не сравним с разрезом скв. Берзини. Дело в том, что среднеордовикские отложения скв. Лудза по литологическим и отчасти фаунистическим признакам относятся к типу разрезов, характерных для переходной полосы между шведско-латвийской и эстонско-литовской структурно-фациальными зонами. Малочисленность фауны из верхнего ордовика этого разреза явно препятствует однозначному решению вопросов корреляции на данном этапе изучения. 


\section{ЛИ Т Е Р А Т Р РА}

Ал и хо в а Т. Н., Б ал аш о в Е. А., Б а л ашов 3. Г. 1954. Полевой атлас характерных комплексов фауны отложений ордовика и готландия южной части Литовской ССР. М.

Г а й л и т е Л. К., У л ь с т Р. Ж. 1972. Предварительные данные о подразделении ордовика в разрезе скв. Лудза (Восточная Латвия). В сб.: Региональная геология Прибалтики и Белоруссии. Рига.

К а льо Д. Л., Кл а а м а н Э. Р., Н е с т о р Х. Э. 1963. Некоторые общие черты фауны кораллов и строматопороидей ашгилля Эстонии и Норвегии. Тр. Ин-та геол. $\mathrm{AH}$ ЭCCP, 13.

К л а а м а н Э. 1966. Инкоммуникатные табуляты Эстонии. Таллин.

М яннил ь Р. М. 1966. История развития Балтийского бассейна в ордовике. Таллин.

М я н п и л ь Р. 1972. Корреляция верхневируских отложений (средний ордовик) Швеции и Прибалтики по хитинозоям. Изв. АН ЭССР, Хим. Геол., 21, № 2.

П ыл м а Л. 1967. О переходной полосе между северной и осевой фациальными зонами ордовика Прибалтики. Изв. АН ЭССР, Хим. Геол., 16, № 3.

П ы л м а Л. 1972а. Состав и количество детрита в отложениях осевой фациальной зоны ордовика Прибалтики (по скважине Энгуре). Изв. АН ЭССР, Хим. Геол., 21, № 2 .

П ылм а Л. 1972б. Состав и количество детрнта в отложениях северной фациальной зоны ордовика Прибалтики (по скважине Рапла). Изв. АН ЭССР, Хим. Геол., 21, № 4 .

Пылм а Л. 1973. Особенности структурно-фащиальных зон Балтийского бассейна в ордовике. В сб.: Фации и геохнмия карбонатных отложений. Тезисы докладов. Л. - Таллин.

С а р в Л. 1959. Остракоды ордовика Эстонской ССР. Тр. Ин-та геол. АН ЭССР, 4.

$\mathrm{Mannil}$, R. 1971. Distribution of selected Ordovician chitinozoan assemblages and species in Northern Europe and their stratigraphic evaluation. Mém. Bureau Rech. Géol. et Minières, № 73.

L. POLMA, L. SARV, Linda HINTS

BERZINI (KAGU-LÄTI) PUURSUDAMIKU ORDOVIITSIUMI SETETE LIIGESTUS

Artiklis antakse Berzini puursüdamiku ordoviitsiumi setete detailne litoloogiline kirjeldus ning stratigraafiline liigestus olulisemate faunarühmade jaotumuse alusel.

\section{POLMA, L. SARV, Linda HINTS}

\section{THE SUBDIVISION OF THE ORDOVICIAN IN THE BERZINI BORING (SOUTH-EAST LATVIA)}

Ordovician deposits in the Berzini boring are of great interest, first of all due to new lithological and paleontological information obtained from the region where these data were so far little known.

A detailed lithological characterization of the rocks in the studied sequence has been presented. In comparison with the northern and western regions of the Baltic basin, the rocks here are relatively terrigenous, represented mainly by greatly clayey limestones and calcareous marls.

The subdivision of the Ordovician deposits in the Berzini boring into stages from Idavere to Vormsi (Caradocian), with the distribution of macrofossils and ostracodes, is given in the Figure.

On the basis of the general distribution of macrofossils and the range of species, the lower part of the sequence (the interval $457.3-486 \mathrm{~m}$ ) can be divided into the Idavere ( $\mathrm{C}_{\mathrm{III}}$; Ristnacrinus angulatus, Estoniops bekkeri, Saucrodictya sp.), Jōhvi ( $\mathrm{D}_{\mathrm{I}}$; Mastopora concava) and Keila ( $\mathrm{D}_{\mathrm{II}}$; Strophomena cf. asmusi, Sowerbyella cf. trivia) stages. 
The middle, the most fossiliferous part of the sequence (interval $440-457.3 \mathrm{~m}$ ) is characterized by a faunal assemblage that in its specific composition (Rafinesquina poljensis, Howellites wesenbergensis, Chasmops wesenbergensis) is similar to the Oandu (DIII) - Rakvere (E) faunal assemblages of the northern and southern structural-facial belt. This assemblage differs from the latter in the lack of some genera (Leptaena, Boreadorthis) and in the greater stratigraphical range of a number of species than the one known so far.

The replacement of the species characteristical of the Oandu - Rakvere Stage, by Upper Ordovician species does not coincide with the boundary between these stages according to the distribution of chitinozoans, but falls into the lower part of Nabala Stage $\left(\mathrm{F}_{\mathrm{I}} \mathrm{a}\right)$.

The upper part of the Berzini boring (interval $425.7-440 \mathrm{~m}$ ) contains species that do not contradict to the Nabala age of its deposits according to ostracodes.

Analogously with the macrofossils, the ostracode species found may be divided into three assemblages - the Idavere-Keila, Oandu-Rakvere and Upper Ordovician ones. The Idavere-Keila assemblage lies between $457.3-486 \mathrm{~m}$. Of its species, Trianguloschmidtella triangulata, Severella severa, Sigmoopsis sp. n. and Tetrada memorabilis are characteristical of the Idavere and Jōhvi Stages, whereas Rakverella spinosa, Tallinnopsis ovalis and $T$. ordinata belong to the upper part of the Keila Stage.

The Oandu-Rakvere assemblage, which includes Bolbina rakverensis, Disulcina perita, Sigmoopsis granulata, Klimphores minimus, etc., appears fully only in the Rakvere Stage and spreads in the given sequence also to the lower part of the Nabala Stage, to a depth of $435 \mathrm{~m}$. Still, already at the beginning of the Nabala Stage, typical elements of the Upper Ordovician assemblage appear (Brevibolbina dimorpha, Tallinnopsis sp. n., Pelecybolbina sp. n.). Most of the Upper Ordovician species (Disulcina praepommeranica, Cryptophyllus gutta, Distobolbina nabalaensis, etc.) appear only in the middle part of the Nabala Stage, partially even in the Vormsi Stage.

Of the chitinozoan species, Eremochitina dalbyensis from the lower part of the Idavere Stage (depth $477.1-485.0 \mathrm{~m}$ ) and Cyathochitina dispar as the species distributed above the lower boundary of the Nabala Stage (depth $439.8 \mathrm{~m}$ ) have to be mentioned. 